LAWRENCE LIVERMORE N A T IO N A L LABORATORY
Baseline and Lifetime

Assessments for DC745U

Elastomeric Components

Robert S. Maxwell, Sarah C Chinn, Julie Herberg, Chris Harvey, Cindy Alviso, Andrew Vance, Rebecca Cohenour, Mark Wilson, David Solyom

January 11, 2005 
This document was prepared as an account of work sponsored by an agency of the United States Government. Neither the United States Government nor the University of California nor any of their employees, makes any warranty, express or implied, or assumes any legal liability or responsibility for the accuracy, completeness, or usefulness of any information, apparatus, product, or process disclosed, or represents that its use would not infringe privately owned rights. Reference herein to any specific commercial product, process, or service by trade name, trademark, manufacturer, or otherwise, does not necessarily constitute or imply its endorsement, recommendation, or favoring by the United States Government or the University of California. The views and opinions of authors expressed herein do not necessarily state or reflect those of the United States Government or the University of California, and shall not be used for advertising or product endorsement purposes.

This work was performed under the auspices of the U.S. Department of Energy by University of California, Lawrence Livermore National Laboratory under Contract W-7405-Eng-48. 


\title{
Baseline and Lifetime Assessments for DC745U Elastomeric Components
}

\author{
Robert S. Maxwell, Sarah Chinn, Julie Herberg, Chris Harvey, Cindy Alviso, \\ Andrew Vance \\ Lawrence Livermore National Laboratory \\ Livermore, CA 94550 \\ Rebecca Cohenour, Mark Wilson, and David Solyom \\ Honeywell Federal Manufacturing and Technologies Kansas City Plant \\ Kansas City, MO
}

\begin{abstract}
The silicone elastomer Dow Corning DC 745U is used in two major components in the W80. We have investigated a number of issues concerning this material. Our studies have accomplished a baseline study of the chemical composition of DC745 and LLNL now has a good understanding of the chemical composition of this material. DC745 crystallizes within the system STS. Two potential means identified to mitigate the risk associated with this phenomenon are to 1) change material formulation and 2) predose the parts to $\sim 25 \mathrm{MRad} \gamma$-radiation. A candidate material identified by Gordon Spellman has been studied for composition and the lack of crystallization within the STS has been verified. A sensitivity study of the effects of relevant aging mechanisms also has been performed. The extent of aging due to radiation exposure or elevated temperatures is minimal over the expected course of the LEP. In addition, since the DC745 parts are expected to be replaced at rebuild, the aging clock is essentially being reset. No significant aging issues seem likely to develop for these parts. DC745 parts are also subject to permanent deformation in service. Our studies have shown that the deformation is likely due to incomplete mixing of the raw gum stock and the curing agent at production. This results in areas of low crosslink density that are subject to a higher degree of compression set in service. We have identified two production diagnostic tools based on Nuclear Magnetic Resonance spectroscopy to prescreen the parts at production at KCP. These studies are concluded with specific recommendation for changes to core surveillance for this part based on the chemical knowledge we have gained from this study.
\end{abstract}




\subsection{Introduction and Executive Summary}

The silicone elastomer Dow Corning DC 745U is used in two major components in the W80 as described in the W80 Certification Plan: the Outer Pressure Pad (OPP; part number: 422431) and the aft cap support (ACS; part number: 422142) [1]. Production specification for the material and the molded parts are described in KCP document \#4155851 - 4155854 ISSUE R [2]. These specifications can be found as Appendix A to this document.

Three major issues have been identified for DC745 within the context of the materials various service requirements:

(1) Since DC745 is a fairly standard, yet proprietary, commercial silicone elastomer, there exists only a limited amount of historical data on the chemical composition and network structure of this material. The network structure of elastomers, unfortunately, is a key variable in determining material properties.

(2) Though siloxane material formulations, in general, have been studied for decades in the academic polymer literature and are considered good general purpose elastomers with excellent compatibility and aging properties, little data, however, is directly available on aging in warhead environments. Surveillance testing (see Figures 1 and 2) of DC745 parts has, in fact, shown both the onset of permanent deformation in the OPP and time dependent changes in load retention in the OPP and ACS. Prior to this study, no molecular level understanding of the causes of these effects existed.

(3) DC745U crystallizes at relatively high temperatures $\left(\sim-40^{\circ} \mathrm{C}\right)$ and has driven the consideration of acceptable replacement materials.

A detailed experimental plan was developed to address these three issues and the results of that study are reviewed in this report. Further, in depth details are reported separately [3-6]. First, we present a brief review of the surveillance data followed by new analysis of surveillance return parts. A review of the composition and structural insight we have obtained via Solid Phase MicroExtraction Gas Chromatography/Mass Spectrometry (SPME-GC/MS), Nuclear Magnetic Resonance (NMR), Fourier Transform Infrared Spectrometry (FTIR), and Differential Scanning Calorimetry (DSC) on this material is presented. Laboratory aging of samples have been employed to fill holes in current understanding of the magnitude of postulated aging mechanisms on material properties. Finally, a review of crystallization phenomena in DC745 and 
characterization of replacement materials designed to prevent crystallization within the service temperatures specified by the STS are presented.

The specific conclusions reached in this study are as follows:

1) DC745 chemical composition has been assessed. LLNL now has a good understanding of the chemical composition of this material. This data will help any future efforts to reverse engineer a suitable replacement material and help predict aging and compatibility for weapon complex needs.

2) DC745 crystallizes within the relevant system STS. Two potential means to mitigating any risk associated with this phenomenon are to 1) change material formulation and 2) predose the parts to $~ 25$ MRad $\gamma$-radiation. A candidate material identified by Gordon Spellman has been studied for composition and lack of crystallization within the STS has been verified. No aging or compatibility data for this replacement material currently exists and its use without such data constitutes an additional potential risk.

3) A sensitivity study of the effects of relevant aging mechanisms has been performed. The extent of aging due to radiation exposure or elevated temperatures is minimal over the expected course of the LEP $[3,4]$. In addition, since the DC745 parts are expected to be replaced at rebuild, the aging clock is essentially being reset. No significant aging issues seem likely to develop for these parts.

4) We have investigated the deformation of these parts observed in service. The deformation is likely due to incomplete mixing of the raw gum stock and the curing agent at production. This results in areas of low crosslink density that are subject to a higher degree of compression set in service. We have identified two production diagnostic tools based on Nuclear Magnetic Resonance spectroscopy to prescreen the parts at production at KCP [5,6].

5) We have made specific recommendations for changes to core surveillance for this part based on the chemical knowledge we have gained from this study. These are outlined in Section 4.1.1, below. 


\subsection{Materials and Methods}

\subsection{DC745}

OPP Surveillance return material was obtained from KCP in 1 x $1 \mathrm{~cm}$ samples. New DC745U squares were obtained from polymer production group at KCP and were cured from Dow Corning 745U silicone fluid cured with Luperox 101, Varox DBPH peroxide curing agent. The curing agent is an organic peroxide supported on $\mathrm{CaCO}_{3}$ that is mixed with the raw gum stock at production. The limited QA/QC requirements for the starting materials and the final product are documented in the material specifications at KCP - see appendix A [2].

\subsection{UNI samples}

Prospective OPP replacement materials were obtained from General Seal Company, Inc (Anaheim, CA). The formulation is, to date, proprietary. However, it is believed a blend of two gums, one of which contains phenyl siloxane monomers. The addition of phenyl groups is well known to hinder the development of crystallinity in silicone elastomers [7]. The curative is most likely via standard peroxide routes [8]. Four candidate materials were obtained - UNI620-1, UNI620-2, UNI620-3, and UNI620-4. These materials differed primarily in phenyl content [see below, section 3.6]. Specific formulation details can be obtained from General Seal for \$30K (2004 dollars). The specifications from General Seal are currently limited to the following data:

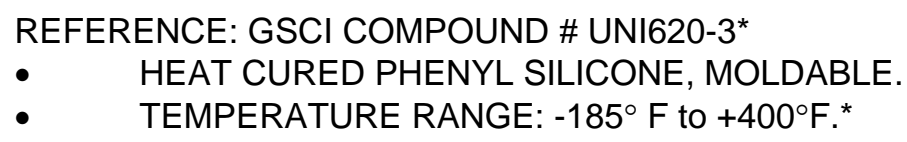

THE ABOVE REFERENCED MATERIAL IS SUITABLE FOR HIGH ALTITUDE APPLICATIONS WHERE EXTREME TEMPERATURE CONDITIONS ARE PRESENT. ${ }^{*}$ GEHMAN TEST RESULTS SHOW NO APPRECIABLE STIFFENING BETWEEN THESE TEMPERATURE RANGES (LISTED ABOVE.)

\subsection{Experimental methods}

In general our aging and baselining studies involve the use of SPME-GC/MS, FTIR, NMR, DSC, DMA, and solvent swelling experimental methods. Details of the experimental methods can be found in a number of our prior publications [3-6, 9-12]. 


\subsection{Results and Discussion}

A

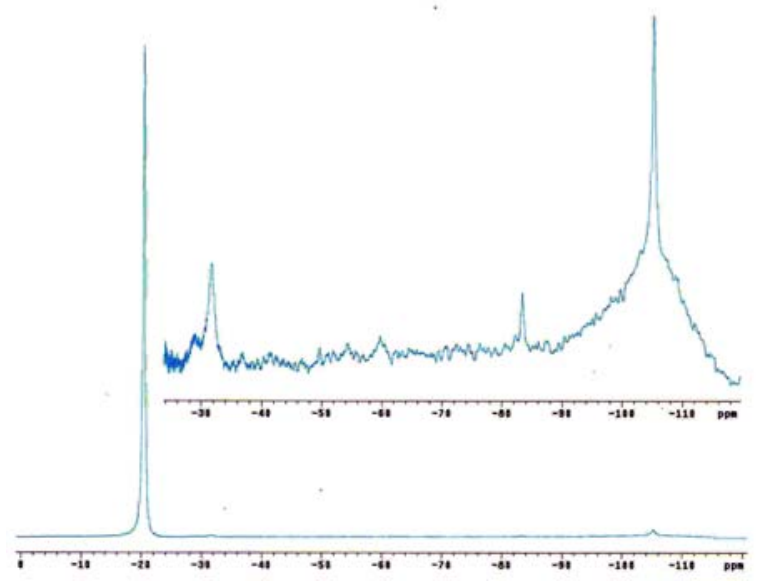

B.

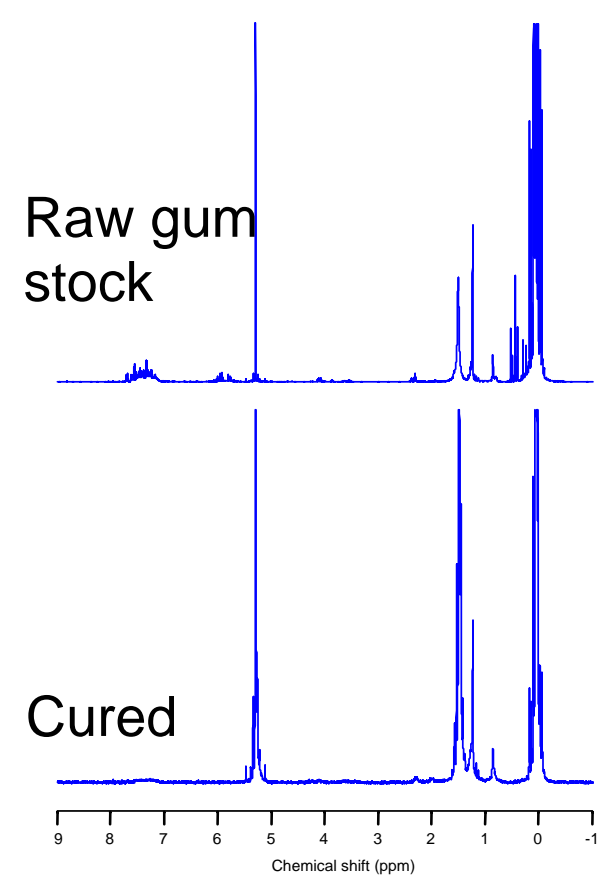

Figure 1. (A) ${ }^{29} \mathrm{Si}\left\{{ }^{1} \mathrm{H}\right\}$ solid state MAS NMR of DC745 Gum stock; (B) ${ }^{1} \mathrm{H}$ solution state NMR of DC745 lots extracted in $\mathrm{CD}_{2} \mathrm{Cl}_{2}$.

\subsection{Chemical Analysis of} composition

This material is known to be composed primarily of long chains of polydimethyl siloxane (PDMS) monomers crosslinked by the addition of the vinyl specific peroxide curing agent (Luperox 101, Varox DBPH, supported on $\mathrm{CaCO}_{3}$ ). Little information beyond this is available from Dow Corning. Initial studies at LLNL, $\mathrm{KCP}$, and LANL have determined additional insight, however. From ${ }^{29} \mathrm{Si}\left\{{ }^{1} \mathrm{H}\right\}$ solid state MAS NMR, as shown in Figure 1A, it has been determined that there is a small amount of phenyl-methyl siloxane monomers (peak at -38 ppm) in the blend/copolymer and approximately 30 wt.\% $\mathrm{SiO}_{2}$ filler (a mixture of high surface area fumed silica and low surface area quartz filler, as seen in the broad resonance at $-100 \mathrm{ppm}$ and the narrow resonance at $-110 \mathrm{ppm}$ ) [13-15].

${ }^{1} \mathrm{H}$ Solution state NMR shown in Figure 1B has determined that the approximate monomer ratio is 100::1.5 Dimethyl to MethylPhenyl. MQ NMR of the fully cured material and the raw 
gum stock suggests that the network structure of DC745 is fairly complex with at least a bimodal network structure of high crosslink density and low crosslink density - the high crosslink density area has been assigned to polymer chains interacting with the filler surfaces [3, 4]. Fourier Transform Infrared (FTIR) spectroscopy, shown in Figure 2A, confirms the dominant presence of dimethyl monomers, the small portion of phenyl groups, and the presence of condensed silicate as a filler. An idealized chemical structure is shown in Figure 2B as derived from the multinuclear NMR studies. It is unknown if the filler has been pretreated with a silating agent, as is done with both TR55 and M97 based silicones.

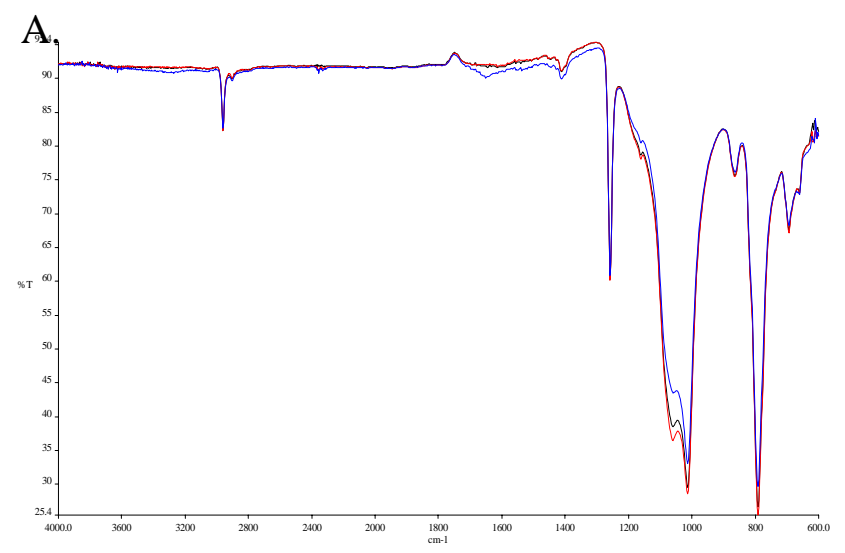

B.

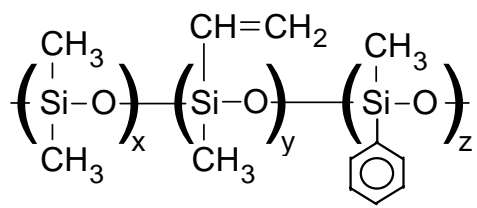

Figure 2. A) FTIR spectrum of three representative DC745 elastomers. B) Relative monomer composition of DC745 as determined here. $\mathrm{X} \sim 100, \mathrm{Y} \sim 1, \mathrm{Z} \sim 1.5$

\subsection{Surveillance Testing}

\subsubsection{Aft Cap Support}

Production and surveillance testing of the ACS is documented in Appendix B and is comprised of measuring a secant modulus at two different segments of a compressions/deflection test [16]. The requirements essentially set only a minimum softness for the part. Nevertheless, results from surveillance are shown in Figure 3 and show a large amount of scatter, but no significant trend with service time. It is postulated that this scatter

is due to testing variances associated either with the testing method itself, or variations due to sample dependent differences (residual talc, trapped air, ect). To date, no statistical assessment of the testing variance has been made. The reported surveillance test results, in addition to this high degree of scatter, also have very little information content of value for determining lifetime estimates. The surveillance testing requirement serves little more than a green light-red light diagnostic.

\subsubsection{Outer Pressure Pad}


The outer pressure pad production and surveillance test is documented in Appendix B and is comprised of a compression test in which the load is determined at two different compressed thicknesses [16]. Results of the surveillance testing on the OPP are shown in Figure 4 and are characterized by even more scatter than was evidenced in the ACS data. A linear regression fit to the surveillance data predicted a load retention at 50 years of $25 \%$. The same reservations noted on the ACS testing methods are also relevant for the surveillance testing for the OPP: testing variance is unquantified, no controls are specified in the surveillance requirement for venting trapped gases or removing residual talc, test result reporting is inadequate for lifetime needs.

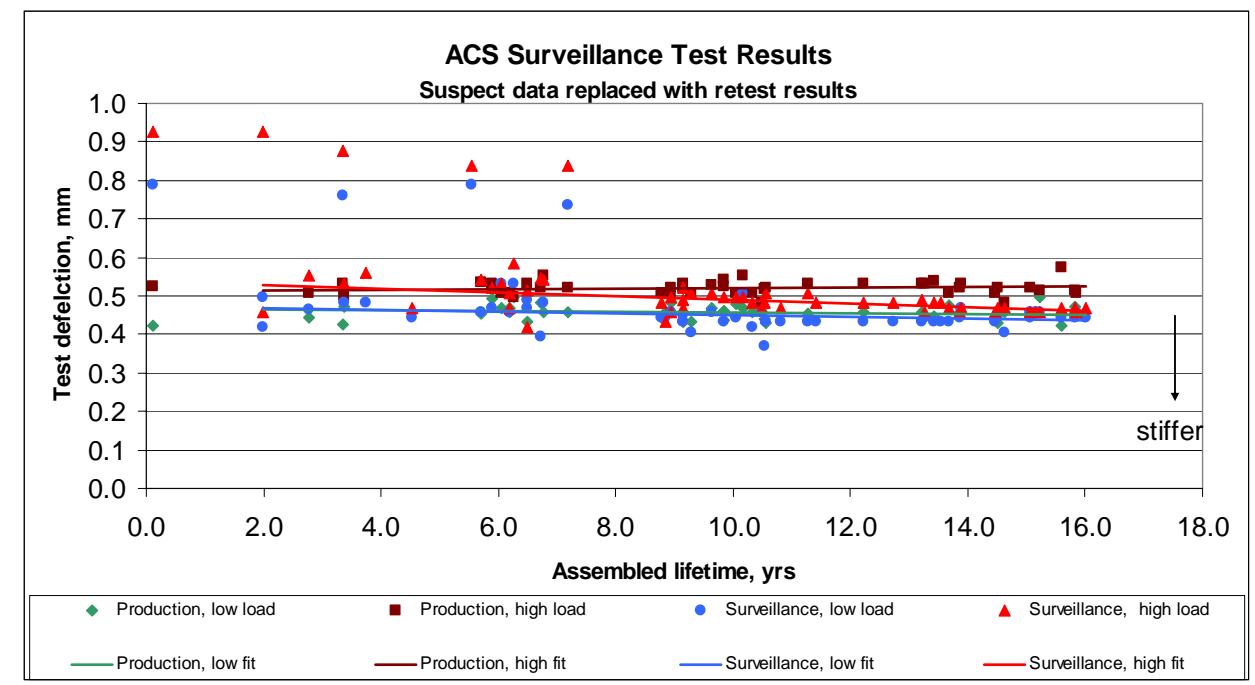

Figure 3. Corrected surveillance testing results on Aft Cap Support.

Data courtesy of G. Spellman.

\subsubsection{NMR analysis of surveillance return parts}

As noted above and shown in Figures 3 and 4, results of surveillance testing are characterized by a large degree of scatter. The surveillance results provide little indication of aging trends, but the large scatter provides little insight and is close to uninformative. (A separate assessment of surveillance testing method variance and the potential sources of variability are being initiated under a separate effort [17].)

Numerous aging mechanisms potentially could limit the lifetime of the OPP and ACS, including radiative crosslinking or chain scission reactions, thermally induced chain scissioning, chemical or physical long term stress relaxation, and chemical incompatibility - see Appendix C. None of these mechanisms are measured by the current surveillance methodology employed for 
these parts. To assess the surveillance parts for chemical aging trends, small segments were tested by ${ }^{1} \mathrm{H}$ NMR transverse relaxation times. The ${ }^{1} \mathrm{H}$ relaxation times are a convenient, indirect

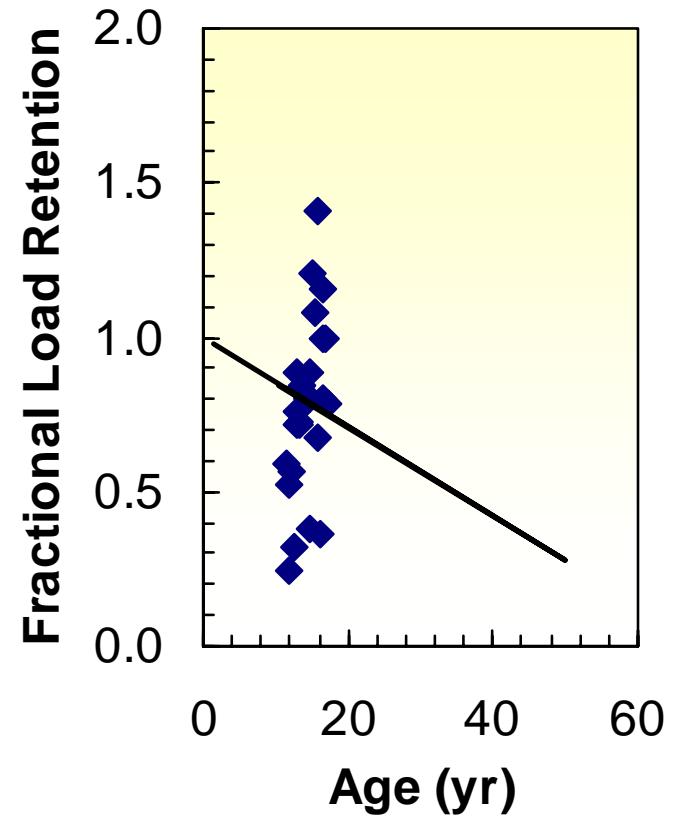

Figure 4. Surveillance testing results for the OPP. measure of the average crosslink density and are insensitive to part shape unlike more traditional techniques, such as DMA $[3,4,18]$. The inverse relaxation times for surveillance return OPP parts are shown in Figure 5 as a function of time in service. The data suggests that the average crosslink density as measured by the NMR method is essentially unchanged with time and, despite the wide scatter in surveillance testing results, the OPP parts are chemically aging gracefully.

The large degree of scatter in the surveillance data and the lack of such scatter in the NMR data further underline the limited value of the current OPP surveillance protocols

for determining material lifetime. Surveillance methods were originally chosen as production QA/QC methods and serve little more than stop-light tests of material performance. Lifetime estimates, on the other hand, require detailed stress-strain data as well as assessments of chemical changes leading to changes in crosslink density. Neither of these are available from current core surveillance requirements. Specific recommendations for changes to surveillance for both the ACS and the OPP are listed in the Conclusion.

\subsection{Laboratory Aging Studies}

In an effort to quantify the boundaries of the changes to component mechanical properties due to relevant chemical degradation mechanisms, a series of laboratory aging experiments was performed. The results of these studies are reviewed below.

\subsubsection{Radiation}

Ionizing radiation is well known to lead to material and dose rate dependent changes in mechanical and chemical properties of polymers due to competing chain scissioning and 
crosslinking

degradation

mechanisms [19]. Though it is generally thought that the radiation environment of the OPP and ACS parts are fairly mild and that radiation induced degradation is minimal in these parts [20], no specific aging study has been reported to validate this assumption. The effect of $\gamma$-radiation on the crosslink density, and therefore the mechanical properties, of DC745 has been investigated indirectly by NMR and the results have been

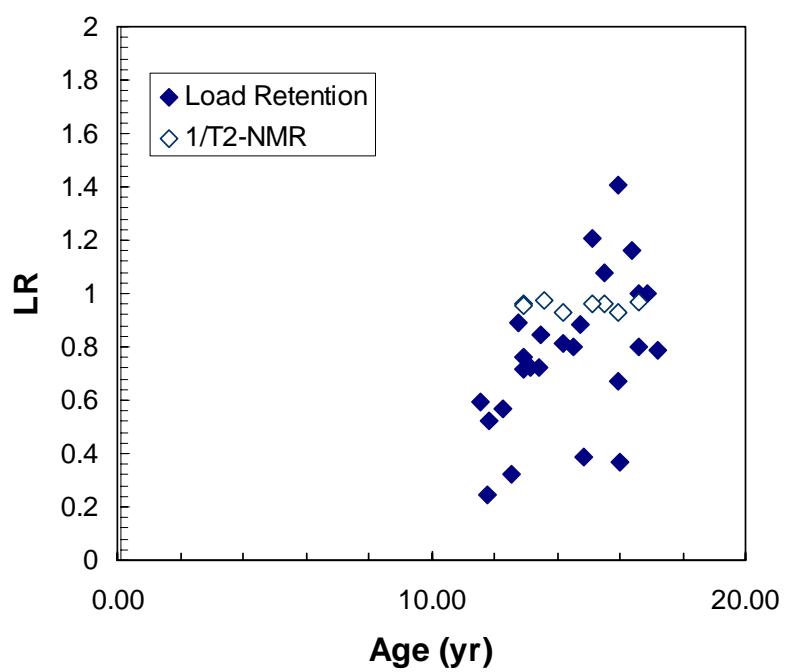

Figure 5. Results of Surveillance testing on outer pressure pad. Closed diamonds are results from standard surveillance methods (see text). Open diamonds are results from NMR studies.

presented in detail elsewhere [3]. The residual dipolar couplings derived from spin-echo relaxation time measurements have shown that radiation induced aging is dominated by crosslinking mechanisms. MQ NMR results have documented additional insight into the distributions of the crosslink density in both the network structure and the polymer interacting with the filler surface [3]. Results from solvent swelling experiments performed at KCP agree with the data presented for the NMR results [3]. The swelling and NMR data clearly indicate that radiation in vacuum leads to reduction in all three measurements of crosslink density. Similar results have been observed in M97, TR55, and RTV-5370 silicones [9-12].

\subsubsection{Radiation and uniaxial strain}

Service environments have been estimated to be much lower over relevant time frames than the 25 MRad cumulative dose used here. The NMR data shown here suggests that the contribution of radiation alone to part failure is insignificant [20]. It has been shown previously, however, that doses of radiation that leave the crosslink density relatively unchanged in siloxane polymers can contribute to an increased amount of compression set and stress relaxation [21]. Results of this study have been reported elsewhere [16], and document that DC745 does take an increased compression set due to the combined effect of radiation and uniaxial strain. A combination of NMR and tensile set measurements were used to quantify the dose dependence of 
the permanent set and additional chemical degradation that occurred during aging. At high doses the increased compression set can be as high as 50\%, though at doses lower than $1 \mathrm{MR}$ the increased compression set is expected to be below an additional $\sim 10 \%$. The NMR results also suggest and increase in the complexity of the network structure which may influence long term
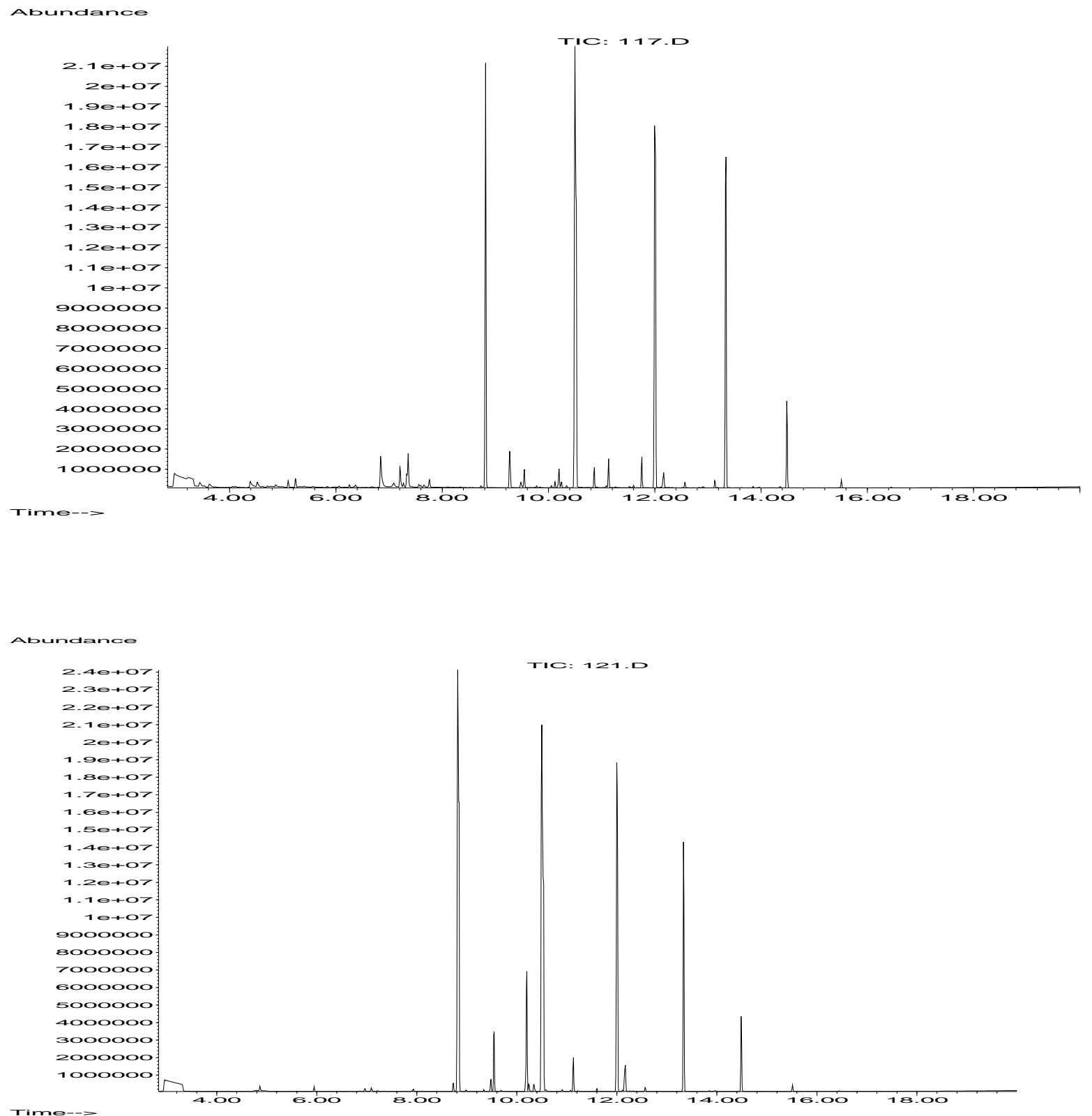

Figure 6 GC chromatogram of thermally aged A) CURED DC745 and B) raw DC745U gum stock.

stress relaxation [4].

\subsubsection{Thermal degradation}


No specific study on the effects of thermal degradation on the mechanical properties of DC745 parts have been performed. Studies on S5370 and M97 based siloxane polymers has shown significant resistance to property deterioration at temperatures below $125{ }^{\circ} \mathrm{C}$, as mentioned above. It is known, however, that transient changes to the network chains can occur that lead to no or small net changes to the crosslink density. These transient changes can lead to significant, long term changes in load retention ability in some polymers [21]. Though no sign of such degradation has been noted in surveillance, the current surveillance testing and reporting requirements would be unlikely to observe such degradation. Toward this end we have used, SPME-GC/MS to assess the low level volatile and semi-volatile degradation products released during long term exposure. These species may provide clues to degradation mechanisms and feed lifetime estimates and diagnostic development and interpretation. A sample chromatagram is shown in Figure 6 and shows that the major degradation products of thermal aging of DC745 are a variety of linear and cyclic siloxane species resulting from the postulated thermally activated backbiting mechanisms illustrated in Appendix $\mathrm{C}$ that maybe occurring. These species are listed in Table 1, below. The loss of these species may lead to long term stiffening of the component due to a the steady loss of small molecules which serve as effective plasticizing agents.

Table 1 Major offgassing species from DC745 when heated for 2 weeks at $70{ }^{\circ} \mathrm{C}$ as determined by SPME sampling and GC/MS analysis.

\begin{tabular}{|l|l|l|l|}
\hline \multicolumn{2}{|c|}{ Raw gum stock } & \multicolumn{2}{c|}{ Cured DC745 } \\
\hline $\begin{array}{l}\text { Retention times } \\
(\text { min) }\end{array}$ & Product & $\begin{array}{l}\text { Retention times } \\
(\text { min) }\end{array}$ & Product \\
\hline $2.97-3.3$ & Benzene & $3-3.3$ & Benzene \\
\hline $6.8-7.8$ & Branched hydrocarbons & 4.8 & Siloxane \\
\hline 8.8 & Siloxane & 8.8 & Siloxane \\
\hline 10.2 & Metal alkyl additive & 9.4 & Metal alkyl additive \\
\hline 10.8 & Dihydroperoxide & 1.0 .2 & Metal alkyl additive \\
\hline 12.17 & Large (C>20) hydrocarbon & & \\
\hline
\end{tabular}

\subsubsection{Deformation studies}


As has been noted in core surveillance, approximately $20 \%$ of OPP parts have been observed to have small regions of permanent deformation [22]. This deformation is characterized by lower than expected thickness (e.g., permanent set), distorted rib shapes, and curling. Given the lack of any aging trends outside the appearance of local deformation, as noted above, the chemical or physical mechanisms responsible for this degradation is the

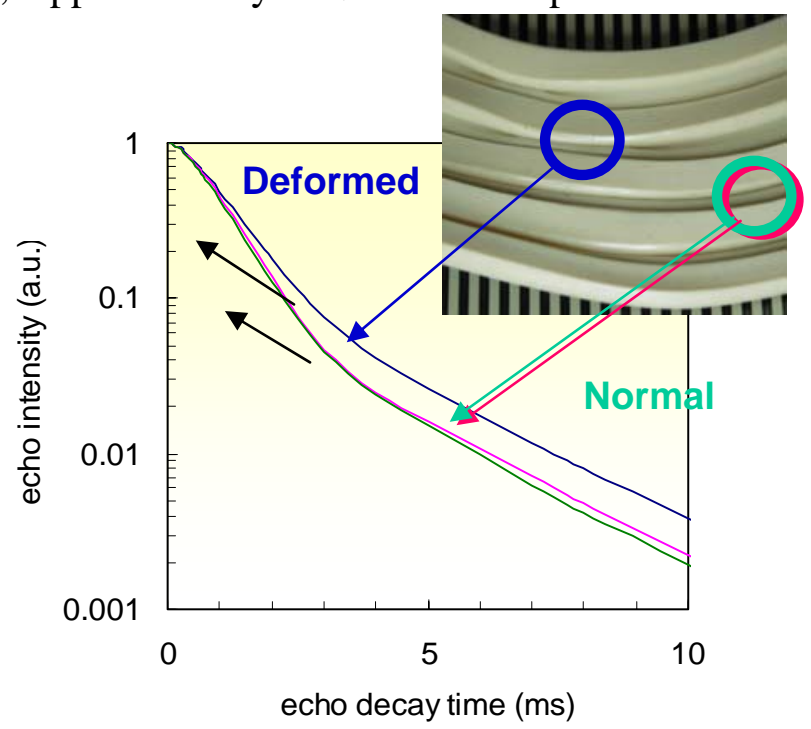
only “aging” trend observed in surveillance. To date, no specific data has been obtained that would point to the origin of this permanent

Figure 7. ${ }^{1} \mathrm{H}$ NMR spin-echo decay curves for damaged OPP deformation. Initial attempts to assess mechanical properties from DMA studies proved unsuccessful due to testing variances associated with the part shapes. NMR analysis, however, provides an indirect measure of crosslink density and mechanical properties that are independent of sample shape.

We have applied NMR ${ }^{1} \mathrm{H}$ spin echo experiments to three DC745U OPP samples: damaged and undamaged sections of a deformed pad and a section from an undeformed pad. The data is shown in Figure 7. The spin echo curves are characterized by a bi-exponential decay that has been observed in previous NMR studies on siloxane polymers. The two populations have been assigned based on these previous studies to a) crosslinked and entangled network species and b) dangling chain ends and low molecular weight chains not crosslinked to the network. The data documents that the undamaged sections are equivalent but different from the damaged section. The NMR data for the damaged section is characterized by a reduced $1 / \mathrm{T}_{2}$ (undamaged, $\mathrm{T}_{2}=1.01$ ms; damaged, $\mathrm{T}_{2}=0.9 \mathrm{~ms}$ ) for the network species and an increased contribution (undamaged, $\mathrm{X}_{\mathrm{sol}}=0.05$; damaged, $\mathrm{X}_{\mathrm{sol}}=0.15$ ) due to the non-network sol fraction.

The NMR data strongly suggests that the physical deformation observed in these materials is accompanied by a decrease in crosslink density and an increase in the non-network species 
population. These changes are consistent with either a degradation pathway that favors chain scissioning reactions or a reduced crosslink density due to poor crosslinking during formulation, likely due to a localized deficiency in the peroxide curing agent or vinyl concentration during mixing. That this localized deficiency is the cause of this deformation has been supported by laboratory efforts to mechanically induce localized damage by overstressing properly cured material [23].

\subsubsection{Catalyst level studies}

In an effort to confirm that incomplete curing of the DC745U resin may be responsible for the areas of permanent deformation, we studied a series of control materials produced with a

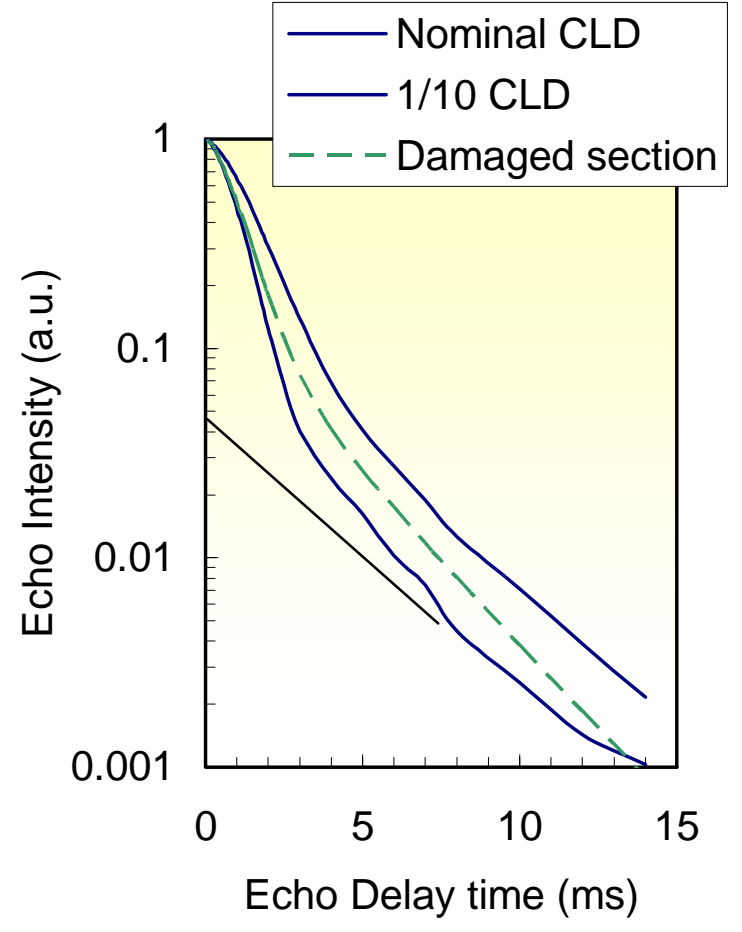

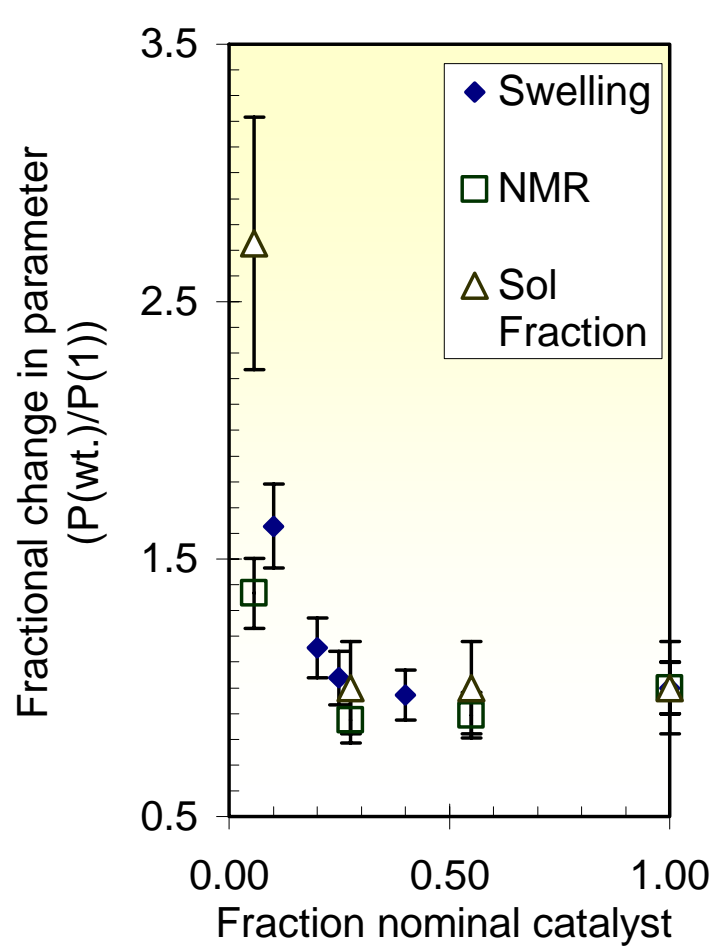

Figure 8 results of NMR studies of model materials (A) spin-echo decay curves; (B) extracted fitting parameters from spin echo decay curves [3-6]

range of peroxide catalyst amounts. The average crosslink density has been determined by solvent swelling in toluene to determine the change in total crosslink density via the indirect parameter of the increase in swollen volume upon immersion in toluene. The results are shown in Figure 8B. These results are not surprising given that the crosslinking mechanisms is by traditional vinyl specific peroxide which have been shown to be nearly independent of peroxide 
content until exceedingly low contents and due primarily to the vinyl content of the gum stock [8]. The solvent swelling results are supported by the trends observed by NMR spin-echo curves shown in Figure $\mathbf{8 A}$ and the results of deconvolution of the decay curves shown in Figure 8B.

However, the NMR curves also show that the so-called sol fraction is catalyst dependent as well as the modulus and the relaxation time. The full spin echo decay curves shown in Figure 8A are directly compared to the decay curves obtained for the damaged and undamaged sections and show that the damaged sections have

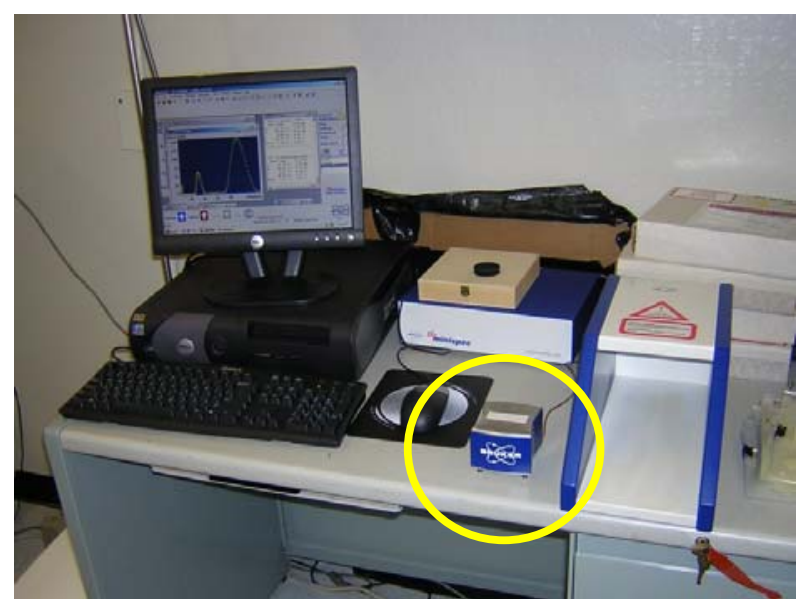

Figure 9. The NMR MOUSE. Polymeric materials are placed on MOUSE (outlined) and scanned via low field spin-echo relaxometry methods discussed in test. chemical compositions between the normal cured material and the material cured with $1 / 10^{\text {th }}$ the nominal catalyst level. From the swelling and NMR results obtained in the study of the irradiated samples, these changes are consistent with a 10\% decrease in crosslink density and hardness [3].

\subsection{New Diagnostics}

In the course of studying the OPP deformation, we identified two Magnetic Resonance based diagnostics that might serve as either production or surveillance tools to assess chemical homogeneity and aging in these materials. The first is Magnetic Resonance Imaging and the second is a one-sided low field, portable NMR relaxometer, the NMR MOUSE (MObile Universal Surface Explorer).

Magnetic resonance imaging is well known in the medical field for providing 3D tomographic images that can be weighted by a number of NMR observables, including relaxation times and residual dipolar couplings [23]. MRI obtains such information by applying large magnetic field gradients across the sample of interest. These field gradients induce a position specific resonance frequency to each spin (or proton in this case), which can be reconstructed after the use of a specific pulse sequence to provide a detailed image. We applied $\mathrm{T}_{2}$ weighted single point imaging methods to a test sample that was constructed of a small piece of nominal crosslink density DC745 and a small piece of DC745 cured with $1 / 10^{\text {th }}$ the normal amount of 
catalyst. We have also performed MRI experiments on deformed and non-deformed pads and have been conclusively able to resolve the regions of reduced crosslink density [5]. MRI systems are available large enough to nondestructively image an intact OPP, however, these imagers are quite expensive (\$1.2-1.8M).

The NMR Mouse, shown in Figure 9, uses the principles of nuclear magnetic resonance for the analysis of arbitrarily large samples. The NMR MOUSE consists of a handheld permanent magnet equipped with a surface rf coil used to measure relaxation parameters (such as $\mathrm{T}_{1}, \mathrm{~T}_{2}$, and $\mathrm{T}_{1 \rho}$ ) from a roughly $1.5 \mathrm{~cm}^{2}$ area. Originally developed by Blümich et al. and marketed in cooperation with Bruker Optics Minispec Division, the MOUSE finds routine uses in the tire industry as a QA/QC tool and in the food industry as a tool for measuring water and fat contents [24]. One of the most prominent uses of the MOUSE is in the polymer industry, as NMR relaxation parameters can be directly correlated to mechanical information such as crosslink density and storage and loss moduli. The advantage of the NMR MOUSE is its low cost and small footprint.
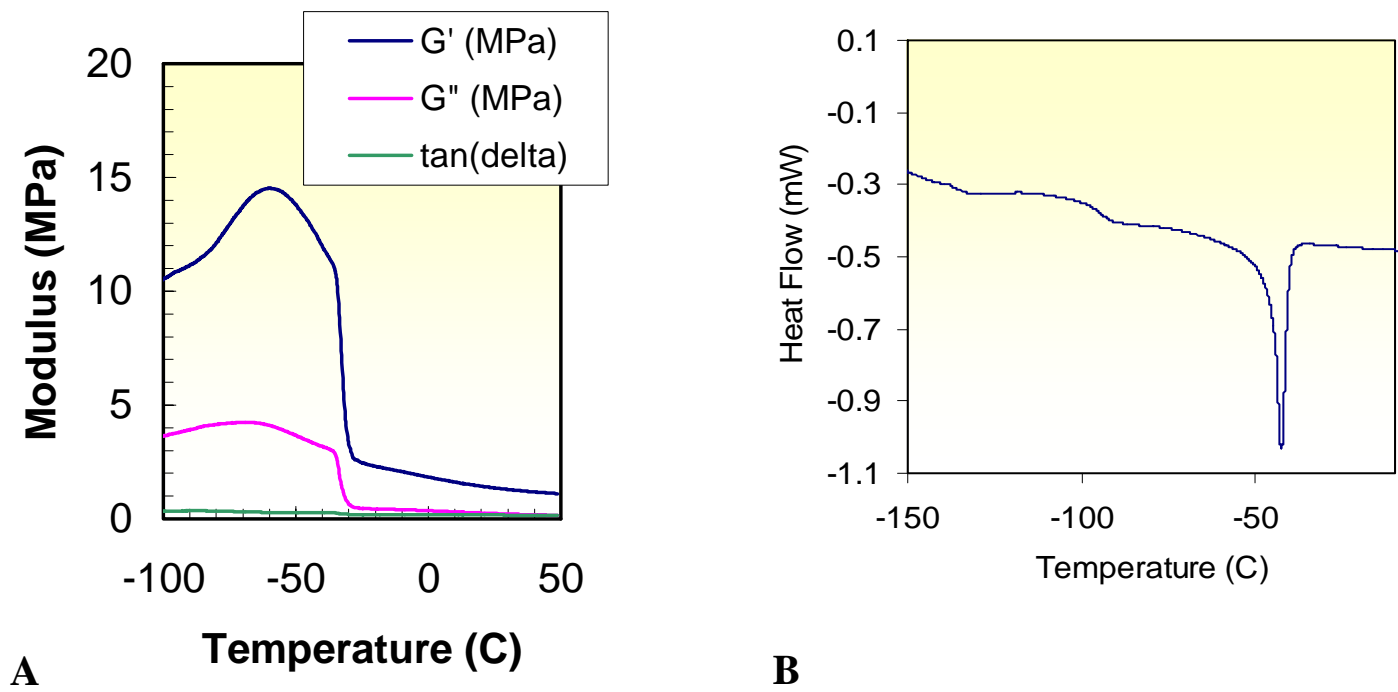

B

Figure 10. DMA studies of DC745 Crystallization. A) Storage and loss modulus and $\tan (\delta$ a function of temperature; crystallization clearly indicated in increase in modulus at $-40{ }^{\circ} \mathrm{C}$. DSC thermogram of DC745 showing crystallization at $-40{ }^{\circ} \mathrm{C}, \mathrm{T}_{\mathrm{g}} \mathrm{S} @-120^{\circ} \mathrm{C}$ and $-90{ }^{\circ} \mathrm{C}$

Details of our efforts using the NMR MOUSE to characterize the deformation of the OPP are documented elsewhere [6]. The histograms obtained via the NMR MOUSE clearly indicate 
differences in average $T_{2} S$ and in the distributions of those $T_{2} S$ between both model samples and actual pads damaged in service. We are currently working to quantify the acceptance criteria and testing requirements for implementing the NMR MOUSE at KCP for OPP diagnostics at production and at surveillance.

\subsection{Crystallization}

\subsubsection{Nominal DC745}

It has been shown (Figures 10A and B) that DC745 crystallizes at $\sim-45^{\circ} \mathrm{C}$ by both DSC and DMA studies. The crystallization rate as observed by isothermal DMA at $-40{ }^{\circ} \mathrm{C}$ is very rapid, as can be seen in Figure 11. In addition to the observed increase in storage modulus of an order of magnitude, the CTE is also expected to change as the material crystallizes.

\subsubsection{Irradiated DC745}

Radiation induced crosslinking has been shown to slow down or even prevent crystallization in silicone material [11,12]. It has been shown for similar materials (M97, S5370) that the crystallization kinetics and temperature are related to the average crosslink density [25]. As the distance between crosslinks increases, the ability of the polymer chains to reorder and crystallize increases and crystallization kinetics increase and crystallization temperatures increase. The DSC thermographs for the irradiated DC745 samples are shown in Figure 12 and clearly indicate a dose dependent change in crystallization temperature that by 25 MRad, crystallization has moved outside the normal operating temperatures expected for this material. If a suitable irradiated source was available and the increased Modulus could be tolerated, preirradiating the OPP to 25 MRad would serve to reduce the crystallization temperature outside the STS limits.

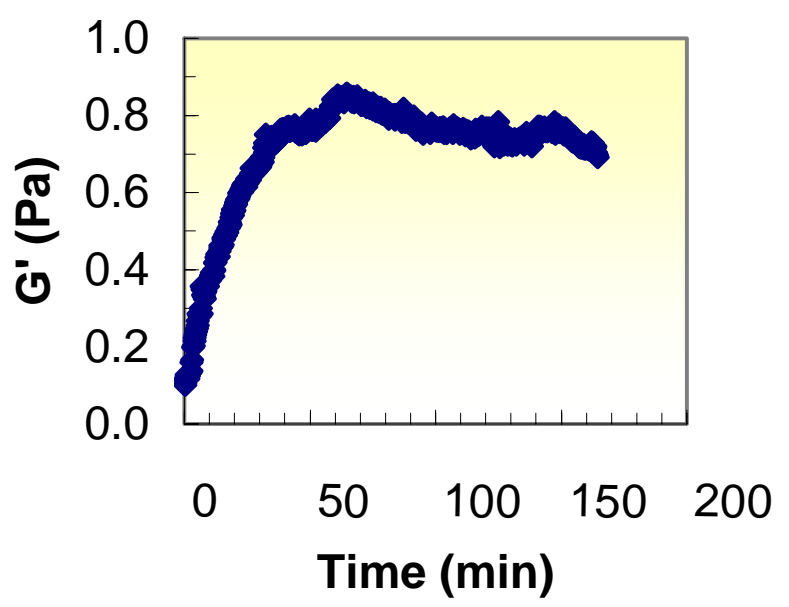

Figure 11. Isothermal DMA of rate of crystallization

\subsubsection{Control DC745}




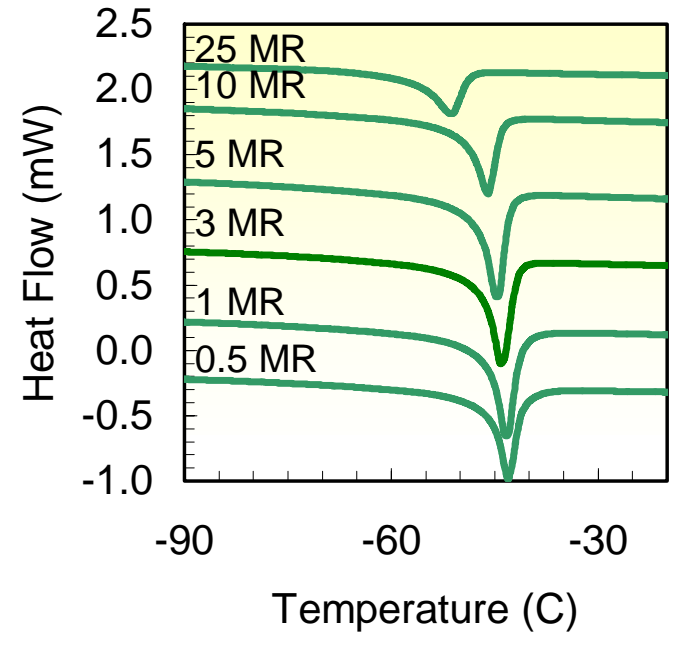

Figure 12. DSC thermograms of irradiated DC745
The dependence of crystallization temperature on crosslink density was also observed in the variable catalyst level control samples, as shown in Figure 13. As expected, reducing the crosslink density of these materials decreased the \% crystallinity (as seen in the decrease in $\Delta \mathrm{H}_{\mathrm{f}}$ for the higher catalyst content samples) and the crystallization temperature.

\subsection{UNI620 Replacement materials}

Results of Differential Scanning Calorimetry are shown in Figure 14A and show that for formulations UNI-2, UNI-3, and UNI-4, no crystallization event was evident. Crystallization however, may be characterized by slow kinetics that may be important on timescales of a few hours, but unobservable on dwell times of a few seconds to minutes typically measured by DSC. To verify that the UNI samples did not

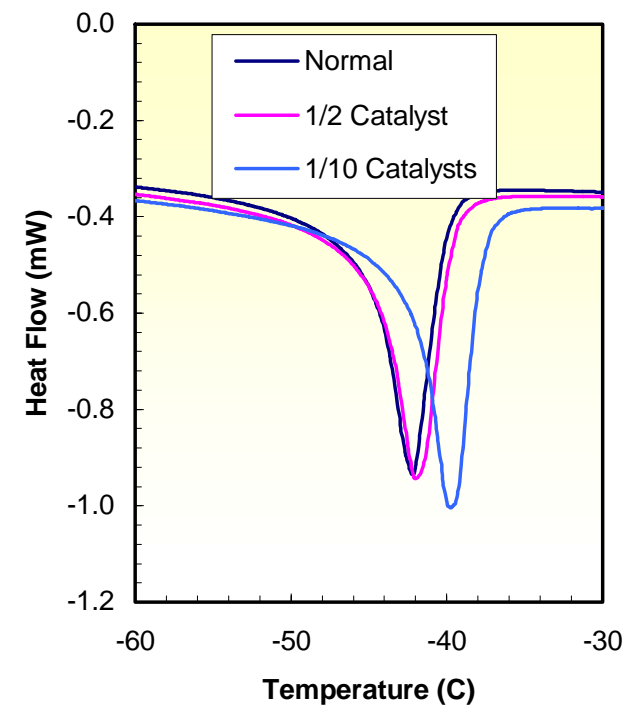

Figure 13. DSC thermograms of model materials crystallize over a longer period, isothermal DMA studies were performed. The storage modulus as a function of dwell time at $-54{ }^{\circ} \mathrm{C}$ is shown in Figure 15. This data shows that the UNI control and UNI-1A samples are subject to rapid crystallization at $-54{ }^{\circ} \mathrm{C}$ over the course of 20 or 30 minutes while the UNI2, UNI-3, UNI-4 samples did not measurably crystallize over the 2 hour run time, suggesting that these samples should not crystallize within normal STS environments.

\subsubsection{Composition and material properties of UNI samples}


Chemical composition and mechanical properties of the UNI replacement materials were then analyzed. The results of room temperature DMA studies are shown in Figure 16 and show that the replacement materials (UNI620-2,3,4) are within $40 \%$ of the control material in modulus. Material UNI-4 had the closest match of the three materials, while UNI-620-2 had the least

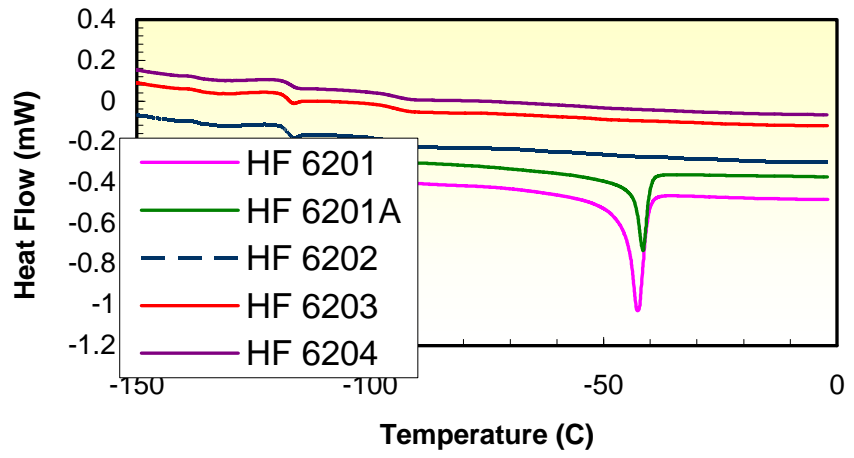

Figure 14. DSC thermograms of UNI replacement material: compatible G'. Other studies by Gordon Spellman have shown that the UNI620-3 sample, however, has the most desirable compression set characteristics [23].

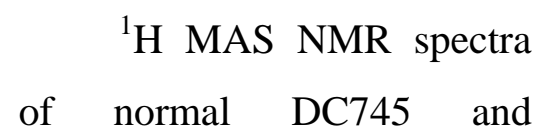
UNI620-3 are shown in Figure 17 and indicate that the UNI sample does indeed have a significantly higher amount of phenyl monomer in the blend composition. Solvent swelling results are shown in Figure 18 and indicate that the UNI-3 has the

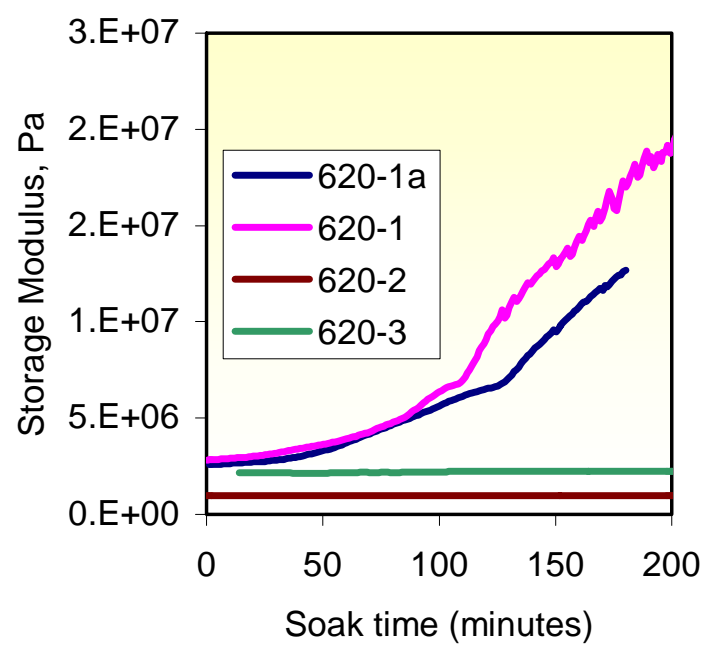

Figure 15. Isothermal DMA studies of UNI replacement materials. highest molecular weight between crosslinks and has a significant amount of filler that interacts with the polymer, but is not covalently bound.

Some limited insight into the network structure was also obtained by DSC analysis. A glass transition will show up most clearly on the Reversing Heat Flow curve in MDSC. Based on that, the UNI620$2,-3, \&-4$ all seem to have a strong $T_{g}$ right 
at the $-115^{\circ} \mathrm{C}$ mark. It also looks like there is another glass transition that starts around $-80^{\circ} \mathrm{C}$ and ends around $-60^{\circ} \mathrm{C}$ on these three samples. The DSC results suggest that these three

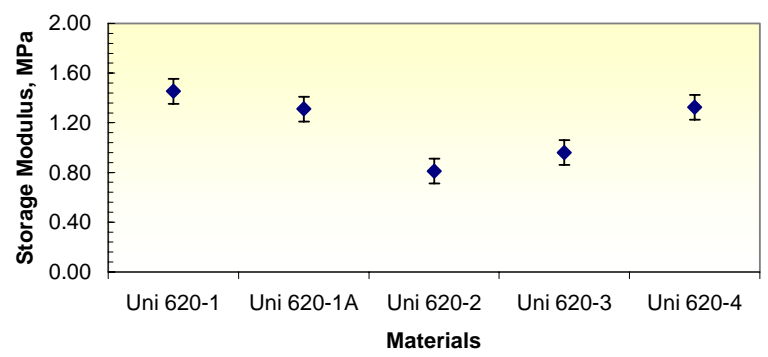

Figure 16. Storage modulus as a function of sample for UNI replacement materials samples are exhibiting co-polymer characteristics with two distinct $\mathrm{T}_{\mathrm{g}}$ 's.

Standard DC745 $<1 \%$ Phenyl

Alt Form-3 $5 \%$ Phenyl

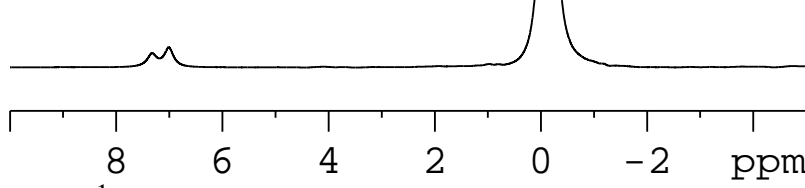

Figure 17. ${ }^{1} \mathrm{H}$ MAS NMR results for replacement materials.
On all of the samples, there is melting activity prior to $T_{g}$ at $-115^{\circ} \mathrm{C}$. This slow event takes place over a 30 degree span between $-150^{\circ} \mathrm{C}$ and $120^{\circ} \mathrm{C}$. At this time the origin of this phenomenon is unknown.

\subsection{Conclusions}

We have characterized the structure and composition of DC745 by a variety of analytical and physical methods. The data indicate that DC745 can be described by a bimodal network structure made up of dimethyl and methyl-vinyl siloxane monomers. The material is reinforced by a mixture of high surface area silica and quartz and is crosslinked via a vinyl specific peroxide curing agent. 
The new data reported here strongly suggests that DC745 parts are aging gracefully. NMR analysis of surveillance return parts indicates no net change over the course of 20+ years in the crosslink density and laboratory aging studies suggest that likely aging scenarios are minor contributors to long term performance.

The likely cause of permanent deformation in surveillance return parts has been determined to be areas of local low crosslink density. Two potential NMR based diagnostics for screening parts at production and for surveillance at tear down have been identified.

Crystallization of the DC745 parts as well as replacement material candidates has been documented, as has results of reverse engineering efforts for the replacement material composition. DC745 crystallizes at $\sim-40^{\circ} \mathrm{C}$, though this value is dependent on crosslink density: higher crosslink density reduces

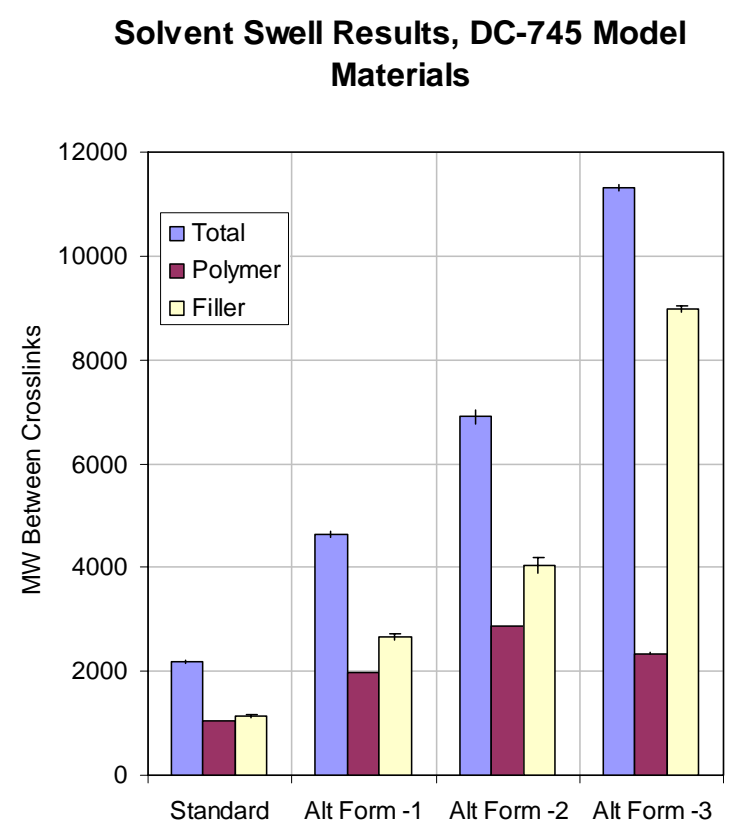

Figure 18. Results of two phase solvent swelling on the UNI replacement materials. crystallinity and melt temperature while lower crosslink density increases crystallinity and melt temperature. The likely DC745 replacement material UNI620-3 has been verified to not crystallize at $-54{ }^{\circ} \mathrm{C}$ at soak times below 2 hours.

\subsection{Recommendations}

\subsubsection{Changes to Surveillance}

It is highly likely that the varied scatter seen in the surveillance testing results is due to testing methodology and does not reflect part performance. Contributions to the testing variance include factors such as the presence of residual talc on surfaces and trapped air venting. Either could easily contribute to the large variations seen in loading and neither are currently controlled for or assessed by current core surveillance requirements. In order to improve the applicability of core surveillance methods to lifetime estimation we recommend that there be (A) an addition of a diagnostic sensitive to chemical aging, e.g. the NMR MOUSE or solvent swelling, (B) a change 
in reporting requirements to provide the entire load-deflection curve for both the OPP and the ACS, (C) a change in testing - e. g. standardization of equilibration time, dusting of parts, ect. to minimize the testing variances, and (D) an detailed quantification at KCP on the testing variances for the methods used in surveillance, old and new.

\subsubsection{Suggested further study}

There is still a need to assess the aging and compatibility of the UNI replacement material in the case that this material is chosen for system rebuild. In addition, it has been noted that the head space contains an unquantified amount of toluene. Toluene can swell silicone parts and the change in mechanical properties, particularly long term, with exposure to toluene should be made. Finally, efforts should continue developing detailed predictive engineering models for material performance over the lifetime of the system, including compression set and stress relaxation that dominate the long time service behavior of the parts.

\subsubsection{Lifetime estimates}

Lifetime estimates for the five likely scenarios for continued use of DC745 are listed below.

1) In the case of no refurbishment, the OPP and ACS would likely serve their intended function as well as they do now (crystallization might still be an issue) for another 20-30 years since no degradation outside of the permanent deformation is observed. The load carried through the OPP should remain at a near constant level - ignoring the expected long time reduction via stress relaxation - averaged over the entire part since the level of compression is so high and that areas of local deformation likely are not leaving gaps but are compressed by local protrusions from nearby components.

2) In the case where the OPP part is retained but reassembled during the LEP refurbishment, there is a potential risk that areas of local deformation will not align with local protrusions that contributed to the deformation and air gaps and loading inhomogeneities may develop in the short term. Otherwise, chemical aging should still be minimal and the lifetime would be an additional 20-30 years.

3) In the case where the OPP is replaced in kind without screening, it is likely that the new lots of material would be subject to the same permanent deformation while in service. Otherwise, the aging clock has been reset and the DC745 pads will last an additional 2030 years with no degradation in performance after the initial compression set of a few percent and the expected long term stress relaxation. 
4) In the case where the OPP is replaced in kind with screening to weed out pads with local areas of local low crosslink densities that may result in permanent deformation, the new pads will last the 20-30 years of the LEP and the incidence of permanent deformation of these parts should dramatically fall off.

5) In the case of replacing DC745 with UNI-3 to control crystallization, little is known about either the long term aging or the compatibility of UNI-3 so no definitive conclusions on the life expectancy of these materials is possible at this time. 


\subsection{References}

1) Wapman, D, Alvarez, J., Rambo, P., Raboin, P., Mclean, W., Healy, T. W80 Mod-3 Nuclear Explosives Package Certification Plan (2003)

2) KCP document \#: 4155851 - 4155854 - see appendix A

3) Maxwell, et al, Radiation induced degradation in a silica-filled silicone elastomer as investigated by Multiple Quantum ${ }^{1} H$ NMR. UCRL-JRNL-208180.

4) Chinn, et al Chemical Origins of Permanent Set in a Peroxide Cured Filled Silicone Elastomer - Tensile and ${ }^{1} \mathrm{H}$ NMR Analysis, UCRL -JRNL-207686.

5) Herberg, et al (2004) Feasibility of Using Magnetic Resonance Imaging as a Diagnostic for Damaged DC745 Components UCRL-TR-207973.

6) Chinn, et al Validation of the Use of the NMR MOUSE for Detection of Inhomogeneities in DC745 at Production, UCRL - TR-208048

7) K. Andrianov, G. Slonimskii, A. Zhdanov, V. Levin, Y. Godovakii, and V. Moskalenko, J. Poly. Sci. A, 10 (1972), 1.

8) Clarson S J, Semlyen J A. Siloxane Polymers New Jersey: Prentice Hall; 1993

9) Chien A, Maxwell R S, Chambers D, Balazs B, LeMay J, Characterization of radiation-induced aging in silicareinforced polysiloxane composites. J Rad Phys Chem 2000; 59(5-6): 493-500.

10) Maxwell R S, Balazs B, Residual dipolar coupling for the assessment of crosslink density changes in $\gamma$ irradiated silica-PDMS composite materials. J Chem Phys 2002; 116: 10492-10502.

11) Maxwell R S, Cohenour R, Sung W, Solyom D, Patel M, The effects of $\gamma$-radiation on the thermal, mechanical, and segmental dynamics of a silica filled, room temperature vulcanized polysiloxane rubber. Poly Deg Stab 2003; 80(3):443-450.

12) A. Chien, S. Deteresa, R. Cohenour, B. Balazs, R. S. Maxwell, Crystallization kinetics in a high phenyl content crosslinked, filled silicone system, J. Poly. Sci. A, submitted (2002).

13) R. Iuliucci, Proton-Silicon Cross Polarization NMR Experiments of DC745u, Presented at the $34^{\text {th }}$ Annual PolyMAC, SNL Albuquerque, NM June 8-10 2004.

14) Maxwell, et al, Enhanced Surveillance Annual Review, 2004, poster presentation.

15) Chinn, et al Characterization, Aging, and Diagnostics for DC745 Silicone Pads, Presented at the $34^{\text {th }}$ Annual PolyMAC, SNL Albuquerque, NM June 8-10 $0^{\text {th }}, 2004$.

16) KCP Surveillance document - see Appendix $B$

17) A detailed effort to quantify variances in current and future surveillance methods is being initiated in support of the W80 LEP. No current funding source has been identified, though Core and Enhanced Surveillance both are vested interests. These efforts should include testing of multiple parts with varying testing conditions to gain insight into the sources of the large scatter seen in all silicone component surveillance testing results.

18) Cohen-Addad J P. NMR and Fractal Properties of Polymer Liquids and Gels, Prog NMR Spect 1993; 25:1316.

19) Evans D, Crook M A, Irradiation of plastics: damage and gas evolution. MRS Bulletin, 1997; 22(4): 36-40.

20) Mount, M., Radiation Dose Modeling of Aged Organics, $21^{\text {st }}$ Aging, Compatibility, and Stockpile Stewardship Conference, Sandia National Laboratories, Albequrque, NM, 1997.

21) Andrews R D, Tobolsky A V, Hanson E E, The Theory of Permanent Set at Elevated Temperatures in Natural and Synthetic Rubber. J. Appl. Phys 1946; 17:352-361.

22) SLT-6, Jan. 1988, W/H serial number 243223, Y-12 report Y/OA-3819.

23) Spellman, G., Baseline and Peer Review Analysis of W80 elastomers, internal report in preparation (2004).

24) Eidmann G, Savelsberg R, Blumler P, Blumich B. The NMR MOUSE, a mobile universal surface explorer. J Mag Res A, 1996; 122:104-109

25) M. Aranguren, Polymer, 39 (1998) 4897. 


\subsection{Appendices}
A. Material Production specification from KCP
B. OPP and ACS surveillance documentation
C. Chemical degradation pathways for silicone materials 


\section{$\underline{\text { Appendix A }}$}

KCP document \# - 4155851 - 4155854

DC745U material specification 
CAGE CODE $14214 \quad 4155851$ - 4155854

M. H. Wilson $834 \mathrm{KC}$

J. A. Emerson 14172SA

L. A. Domeier 8722SL

DRC, 2TIE

Vertical lines in left margin identify changed content. SILICONE, RUBBER (U)

Drawing Callout: Silicone Rubber per 4155851 - 4155854-(1), (2).

(1) Insert applicable Material Specification Number from 1.2.

(2) Insert Control Number Suffix.

CHANGE HISTORY

CONTROL NUMBER ISSUE RELEASE/CHANGE NO. DATE

4155851 - 4155854-02 M 913065KC

N 981989KC 10/98

P 990914KC 06/99

R 20020002KC 01/02

Page 1 of 5 
4155851 - 4155854

ISSUE R

\section{GENERAL.}

Page 2 of 5

1.1. Scope. This specification covers silicone rubbers that achieve an optimum balance of physical, thermal, and electrical properties after press vulcanization. No postcure is required; molded parts made from these rubbers are serviceable over an operating temperature range of -100 480 Deg. F. Both $746 \mathrm{U}$ and $748 \mathrm{U}$ have been discontinued. A $50 / 50$ blend of $745 \mathrm{U} / 747 \mathrm{U}$ may be substituted for $746 \mathrm{U}$.

1.2. Material Specification Number. Spec. Number Durometer Product Hardness Shore A 4155851 Silastic $745 \mathrm{U} 50 \pm 5$ 4155852 Silastic $746 \mathrm{U}$ (DisC.) $60 \pm 5$ 4155853 Silastic $747 \mathrm{U} 70 \pm 5$ 4155854 Silastic $748 \mathrm{U}$ (DisC.) $80 \pm 5$ 1.3. Definition. /M/ is a symbol placed adjacent to a section or paragraph to specifically designate requirements or information pertinent only to $\mathrm{KCD}$.

\section{DOCUMENTS.}

2.1. Required. The following documents form a part of this specification to the extent stated herein: ASTM-D-395-82 Rubber Property-Compression set ASTM-D-412-80 Rubber Properties in Tension ASTM-D-2240-81 Rubber Property-Durometer Hardness 4618050 2, 5-Dimethyl-2, 5-Di (T-Butylperoxy) Hexane 50 Percent Active 
4155851 - 4155854

ISSUE R

Page 3 of 5

\section{REQUIREMENTS.}

3.1. Approved Products. The material shall be one of the following:

Spec.

Number

Product

Designation Company

$4155851745 \mathrm{U}$ Dow Corning Corporation

$4155852746 \mathrm{U}$ (DisC.) "

$4155853747 \mathrm{U}$ "

$4155854748 \mathrm{U}$ (Disc.) "

3.2. Properties. Compounds, catalyzed as indicated in Table 1, then press vulcanized in slabs, approximately 0.075 inch

thick for 10 minutes at $340^{\circ} \mathrm{F}$., shall conform with the properties listed in Table 1 . The properties listed in Table 1 are for acceptance/quality control purposes only and may not represent the physical properties of the finished product due to necessary processing variations. Conformance to these properties merely indicates the bulk material has the capability of producing product of similar physical characteristics when properly processed. 3.3. Specimen Preparation and Conditioning. All specimen preparation, conditioning and testing shall be conducted in a laboratory atmosphere of $24 \pm 6$ Deg. C and a humidity range of 10 to 65 percent.

\section{TABLE 1}

ASTM

Test Silicone Rubber Value

Property Number 745U 746U 747U 748U

(Recommended $0.53 \quad 0.46 \quad 0.43 \quad 0.41$

vulcanizing agent

and ratio)

4618050 per 100 parts

by wt. of base resin

*Durometer Hardness, D-2240 Determine and Report

Shore A

Tensile Strength, psi D-412 700800800850

minimum

Ultimate Elongation, D-412 200160140100

percent minimum

*Compression set, D-395 $15 \quad 152022$

percent max. after 22

hrs. at 350 Deg. F

*Test specimens shall be press cured buttons. 
4155851 - 4155854

ISSUE R

\section{QUALITY ASSURANCE PROVISIONS.}

Page 4 of 5

4.1. Lot Definition. A lot shall consist of a homogeneous quantity of material. Each shipment of material shall be considered a lot. The lot number shall be comprised of both the purchase order number and the manufacturer's lot number, for example, B123456-001/ABC123.

4.2. Lot Inspection and Testing. A representative sample from each lot shall be inspected and tested for conformance with the requirements of Table 1 . 4.3. Test Specimens. Test specimens shall be cut from approximately $6 \times 6 \times 0.075$ inch thick test slabs. Test slabs shall be press-cured for at least $10 \pm 0.5$ minutes at $340 \pm 5$ Deg. F. Buttons for hardness and compression set testing shall be press cured for $20 \pm 5$ minutes at $340 \pm 5$ Deg. F.

4.3.1. The specified formulation and cure condition are given for the fabrication of test slabs/buttons only.

4.4. Compression Set. Compression set tests shall be per ASTMD395, Method B. Compression set specimens consist of a molded circular disk. Type 1 specimens molded to .490 \pm .040 inches thickness shall be used. The spacer bar thickness shall be 0.75 times the actual sample thickness and controlled to \pm 0.001 inch. Report two values. The average value shall be used to determine conformance.

\section{PACKAGING, HANDLING AND STORAGE.}

5.1. Package or Container Identification. Each individual container of material shall be marked with at least the following information:

Material Specification Number

Product Designation

Name of Manufacturer

Manufacturer's Lot Number

Purchase Order Numbers

Date of Receipt

Storage Condition: C2-3

Shelf Life: 13 months from date of receipt 
4155851 - 4155854 ISSUE R

Page 5 of 5

5.2. Shelf Life. The shelf life of this material is thirteen months from the date of receipt. Uncured material not used before the expiration date shall be tested to the acceptance requirements of Table 1 . If the material meets all requirements, the shelf life may be extended an additional three months. If it fails to meet any requirement, it shall be scrapped. The shelf life may be extended a maximum of nine months, then the material shall be scrapped.

\section{END OF TEXT}




\section{$\underline{\text { Appendix B }}$}

KCP documents -

\section{OPP and ACS Surveillance Requirements}


FSCM NO. 88516

1463030

B. BAXTER, 557BX

A. WILSON, WX-1 qivilion

L. BURY 818BX

TIE LANL/BX DRC 2

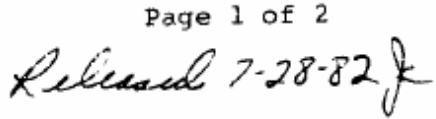

MATERIAL AND TEST REQUIREMENTS FOR PRESSURE PAD 422431

Page 12

issue $A$ A

DESIGN AGENCY

CONTROL NUMBER

ISSUE

RELEASE/CHANGE NO.

DATE

1463030-000

$7 / 82$ 
1463030

Page 2

Issue A

1. GENERAL.

1.1 Scope. T"1is specification covers the material and test requirements for Pressure Pad, $\mathrm{P} / \mathrm{N} 422431$.

2. DOCUMENTS.

2.1 The following documents form a part of this specification to the extent stated herein.

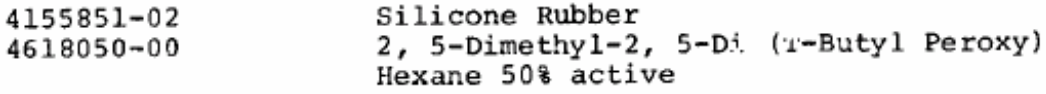

3. REQUI REMENTS.

3.1 Formulation. The compound shall be formulated from the materials listed below, taken in the requisite proportions on a weight basis. The tolerance on the weights of the materials shall be plus or minus one percent.

$$
\begin{array}{ll}
\text { Silicone Rubber, per } 4155851 & 100 \text { parts by weight } \\
\text { Catalyst per } 4618050 & 0.55 \text { parts by weight }
\end{array}
$$

3.2 Load deflection at $25^{\circ} \mathrm{C}$. The part shall meet the requirements set forth in rable I when tested per section 4.

\begin{tabular}{|c|c|c|c|c|}
\hline $\begin{array}{l}\text { Part } \\
\text { Number }\end{array}$ & $\begin{array}{c}\text { Load } \\
\text { (Newtons) }\end{array}$ & $\begin{array}{l}\text { Low Load } \\
\text { Compressed } \\
\text { Height } \\
\text { (MM) }\end{array}$ & $\begin{array}{c}\text { Load } \\
\text { (Newtons) }\end{array}$ & $\begin{array}{c}\text { High Load } \\
\text { Compressed } \\
\text { Height } \\
\text { (MM) }\end{array}$ \\
\hline 422431 & $11,120 \mathrm{MIN}$ & 2.51 & $43,600 \mathrm{MAX}$ & 2.06 \\
\hline
\end{tabular}

TABLE I

4. QUALITY ASSURANCE PROVISIONS.

4.1 Test requirements.

4.1.1 The load versus deflection values shall be determined at $25^{\circ}+5^{\circ} \mathrm{C}$. The part shall be tested between Mylar sheets $0.25 \mathrm{MM} \pm .05 \mathrm{MM}$ thick. The part shall be compressed to a thickness of $2.06 \mathrm{MM}^{-}$three times and the readings taken on the third cycle. The loading and unloading rate on all three cycles shall be $1.27 \mathrm{MM}+0.13 \mathrm{MM}$ per minute loading and $2.54 \mathrm{MM}+0.13 \mathrm{MM}$ per minute unloading. A three minute \pm 15 second dwell shali be included between cycles. 
FSCM NO. 88516

J. Nichols, 557 $\mathrm{BX}^{\mathrm{y}}$

$M$. Wheeler, wX-1,

B. Wilder, $824 \mathrm{BX} 2 \omega$

BKC-WPC II (P3dj)

LANL/BX DRC 2
1461837

Page 1 of 2

Releavel $8-14-8988$

TEST REQUIREMENTS FOR AFT CAP SUPPORT, 422142

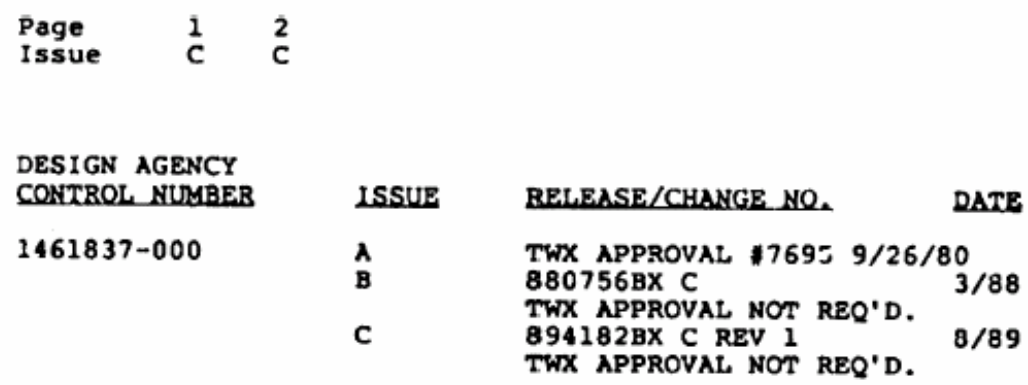

UNCLASSIFIED 
1 .

GENERAL .

1.1 Scope. This specification covers the material and test requirements for the Aft Cap Support, P/N 422142.

2. DOCUMENTS.

2.1

The following documents form a part of this specification to the extent stated herein.

3. MATERIAL.

3.1 Formulation. The compound shall be formulated from the materials listed below, taken in the requisite proportions on a weight basis. The tolerance on the veights of the materials shali be plus or minus five percent. Add acetone, 4616011-01, as required to facilitate the process.
2201225-01
Polyamide Resin
608 by Weight 2140045-01

4. PROCESS REQUIREMENTS.

4.1

Prior to bonding the pressure pad $P / N 1461349$ and the Af $t$ Cap Support $D / N$ 146134B shall be plasma cleaned in an air environment. No more than five grams of adhesive shall be used to bond the two parts together. Bonding shall be accomplished within two hours of cleaning.

5. REQUIREMENTS.

5.1 Load deflection of $25^{\circ} \mathrm{C}$. The part shall have a minimum of $0.355 \mathrm{~mm}$ deflection between the load values of 22,200 and 53,500 Newtons. It shall also have a minimum of $0.405 \mathrm{~mm}$ deflection between the load values of 53,500 and $133,50 n$ Newtons.

6. TEST REQUIREMENTS.

6.1 The load versus deflection values shall be determined at $25 \pm 5^{\circ} \mathrm{C}$. The part shall be cycled to a load of 133,500 Newtons three times and the readings taken on the third cycle. The loadings and unloading rate shall be $1.27 \mathrm{~mm}$ per minute. A one minur \pm 10 second dwell shall be included between sycles.

6.2 Fixture 1461349-GFI shall be used to do the load versus deflection test.

UNCLASSIF:ED 


\section{Appendix $C$}

Postulated Chemical Degradation Mechanisms for DC745 silicone pads 


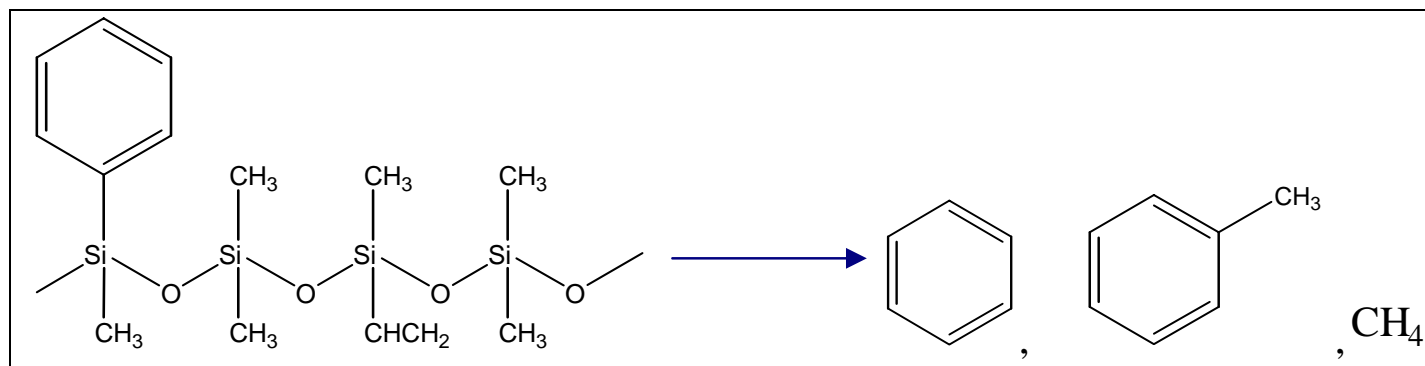

Fragmentation reactions

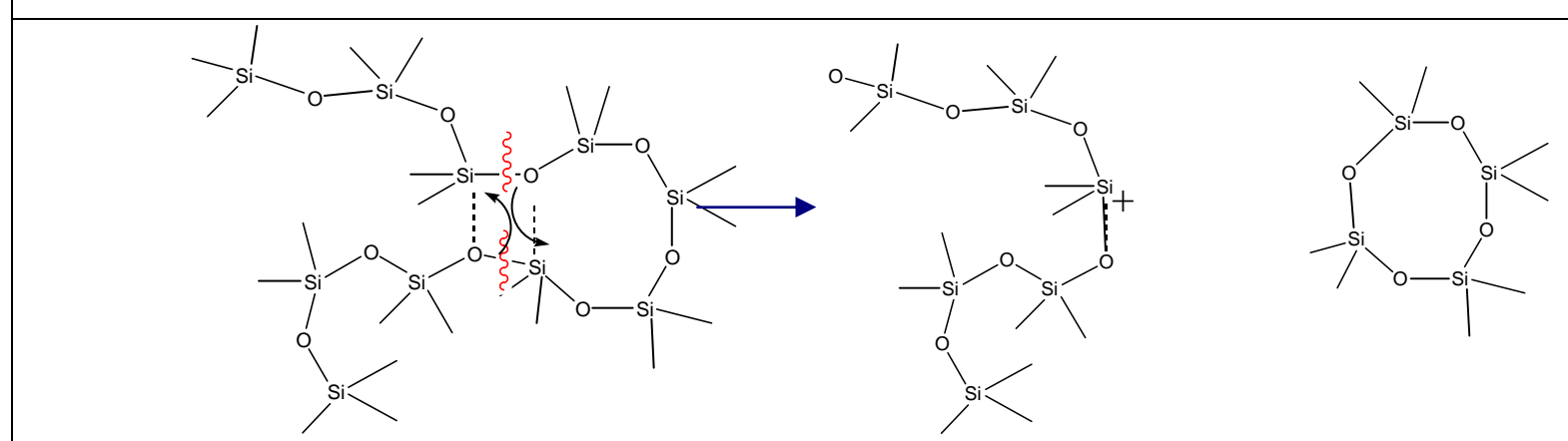

Backbiting/chain scission reactions

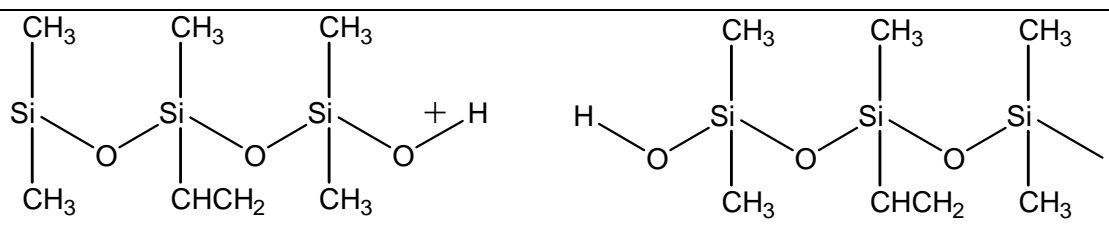

$\downarrow$

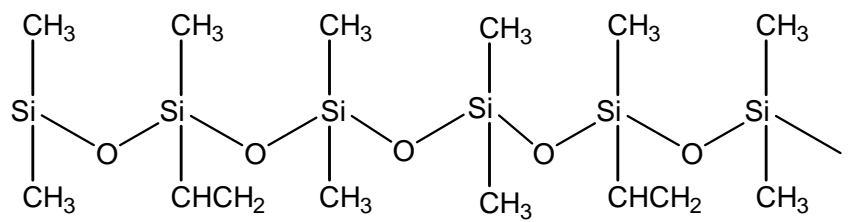

Condensation reactions 


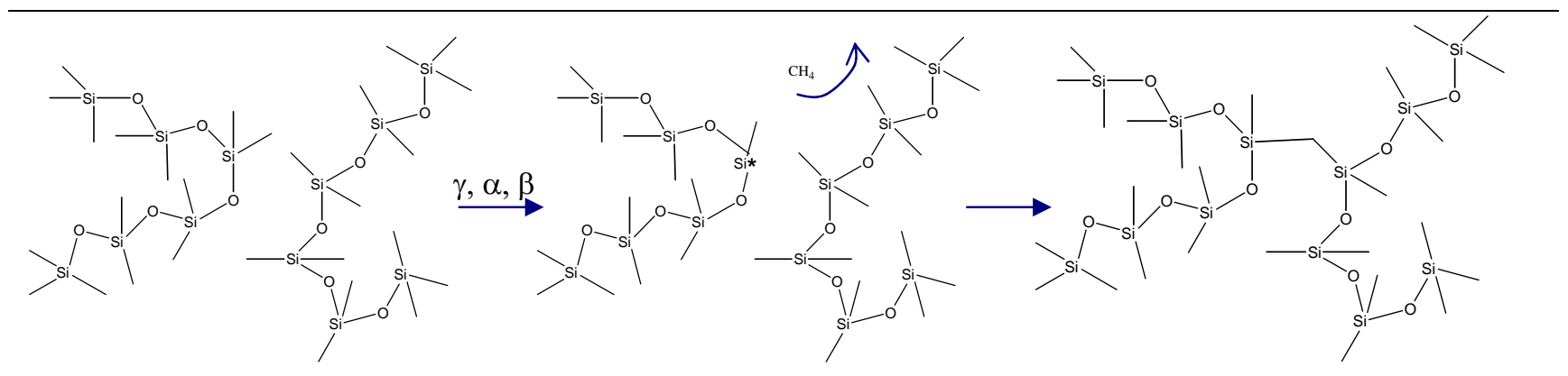

Radiation induced Crosslinking of two chains
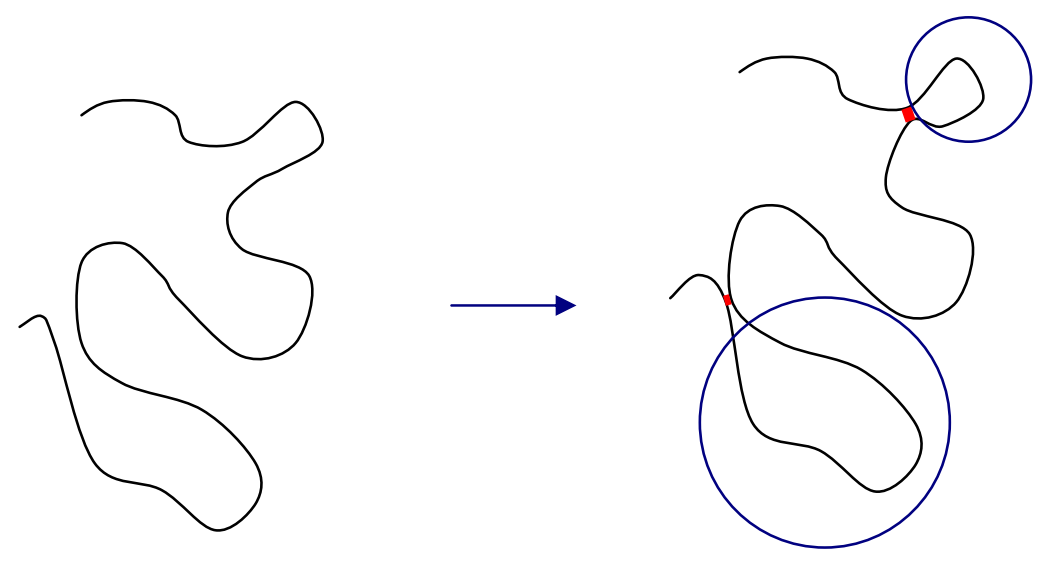

Production of elastically ineffective segments (crosslinks shown in red, ineffective segments circled in blue). 